\title{
Growth and Characterization of Triglycine Sulphate Crystal
}

\author{
C.Besky Job and Shabu \\ Department of Physics, Scott Christian College, Nagercoil, Tamil Nadu, India.
}

\section{Introduction}

Tri Glycine Sulphate (TGS) is a well known ferroelectric and pyroelectric material below its critical temperature $\left(49^{\circ} \mathrm{C}\right)$ [1]. It finds application in the fabrication of infrared detectors, pyroelectric vidicon tube operating at room temperature, in the fabrication of capacitors, transducers and sensors [2-3]. TGS belongs to the biaxial monoclinic system associated with the polar space group $\mathrm{P} 2{ }_{1}$ in the ferroelectric phase and it crystallizes in $\mathrm{P}_{1} / \mathrm{m}$ space group in the paraelectric phase [4-6] . The monoclinic b-axis is known to be parallel to spontaneous polarization direction. Therefore the b-cut (010) crystals are technologically important for many device applications [7-9]. Ferro electric TGS exhibits antiparallel $180^{\circ}$ domains, generally parallel to b-axis. The domains in the majority of the crystals are rod shaped, with lenticular cross sections elongated in the direction perpendicular to the crystallographic c-axis [10]. It was first demonstrated by Le Bihan by scanning electron microscopy technique [11]. The two hydrogen atoms of sulphuric acid of TGS are protonated to the carboxylic group of two zwitterionic molecules, and the carboxylic hydrogen atom combined with the amino group of the third glycine molecule and forms a zwitterions [12]. TGS has some disadvantages such as,

i. Ferroelectric Domains Possess High Mobility At Room Temperature

ii. Easy Depolarization By Electrical, Mechanical And Thermal Means

iii. Microbial contamination during the growth time [13-15].

The characterization studies on TGS crystal [16-18] with dopants such as L-alanine [19], Sodium Bromide [20], Magnesium Chloride [21], Calcium [22], Potassium Bromide [23], Ammonium dihydrogen Phosphate [24], Ammonium Chloride [25], Lithium Sulphate [26], Quanidine [27], rare earth elements [28], Chromium [29], Phosphoric acid [30], L-tyrosine [31], L-Cystine [32], Palladium [33], L-Threonine [34], urea [35], DL-methionine [36], EDTA [37] and DL-Phenyl alanine [38] have been already reported.

In the present study, TGS crystal has been grown by the conventional slow evaporation method. The main objective of the present work is to investigate the effect of the structural, vibrational and mechanical properties of TGS crystals.

\section{Crystal Growth}

The single crystal of Tri Glycine Sulphate has been synthesized by dissolving Glycine and Sulphuric acid in a molar ratio of 3:1 in deionized water. The chemical reaction performs as follows,

$3\left(\mathrm{NH}_{2} \mathrm{CH}_{2} \mathrm{COOH}\right)+\mathrm{H}_{2} \mathrm{SO}_{4}{ }^{\circledR}\left(\mathrm{NH}_{2} \mathrm{CH}_{2} \mathrm{COOH}\right)_{3}\left(\mathrm{H}_{2} \mathrm{SO}_{4}\right)$

A saturated solution was prepared by stirring 8 hours continuously and filtered using whatman filter paper. The solution was allowed for slow evaporation by keeping it in the dust free atmosphere. After three weeks, well transparent, colourless crystals have been harvested. The photograph of the grown TGS crystal is shown in Fig.1.

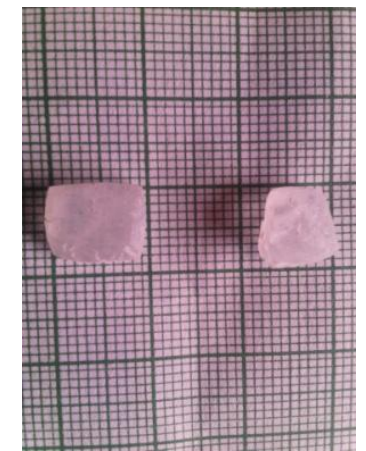

Fig.1 Photograph of the grown TGS crystal 


\section{Material characterization}

The grown TGS crystals were subjected to powder $x$-ray diffraction studies using SEIFERT diffractometer at room temperature with $\mathrm{CuK} \alpha$ radiation of wave length $(\lambda=1.5406 \AA$ ) to confirm the identity of the grown crystal. The single crystal XRD study of TGS crystal was carried out using ENRAF NONIUS CAD4-F single crystal x-ray diffractometer with Mok $\alpha(\lambda=0.7170 \AA)$ radiation. The FTIR spectrum of TGS crystal was recorded in the region $400-4000 \mathrm{~cm}^{-1}$ at a resolution of $\pm 2 \mathrm{~cm}^{-1}$ using Perkin Elmer Spectrophotometer. Hardness of the grown TGS crystal was measured using Leitz - Wetzler hardness tester fitted with a Vickers diamond pyramidal indenter. Indentations were made for various loads from $25 \mathrm{~g}$ to $100 \mathrm{~g}$, the average diagonal lengths were measured for a regular interval of 10 seconds.

\section{X-ray diffraction analysis}

The indexed powder x-ray diffraction pattern for TGS crystal is depicted in Fig. 2. The sharp peaks confirmed the crystalline nature. From single crystal XRD studies it is found that the grown TGS crystal crystallized in monoclinic system with lattice parameters $a=5.732 \AA, b=12.631 \AA \hat{A}, c=9.163 \AA, \beta=105.52 \AA$ and $\mathrm{V}=639.1 \AA^{3}$.

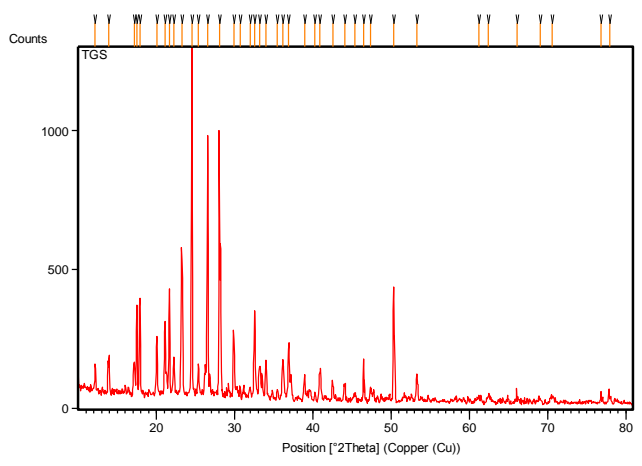

Fig.2 Powder XRD pattern of the grown TGS crystal

\section{FTIR Analysis}

The recorded FTIR spectrum of pure TGS crystal is shown in Fig.3. The band at $3423 \mathrm{~cm}^{-1}$ is assigned to antisymmetric $\mathrm{NH}_{3}{ }^{+}$stretching. The peaks appeared at 3169 and $3009 \mathrm{~cm}^{-1}$ is attributed to symmetric stretching of $\mathrm{NH}_{3}{ }^{+}$. In the region between 2500 and $3400 \mathrm{~cm}^{-1}$, the $\mathrm{OH}$ stretching of carboxyl group, $\mathrm{NH}$ stretching and aliphatic $\mathrm{CH}$ stretching overlap together. The $\mathrm{CH}_{2}$ stretching mode is observed at $2911 \mathrm{~cm}^{-1}$. The peaks at 2705 and $2611 \mathrm{~cm}^{-1}$ are due to $\mathrm{NH}_{3}{ }^{+}$overtones and combination bands. The $\mathrm{C}=\mathrm{O}$ stretching of $\mathrm{COOH}$ group is observed at $1596 \mathrm{~cm}^{-1}$. The bending mode due to $\mathrm{NH}_{3}{ }^{+}$are clearly seen at $1517 \mathrm{~cm}^{-1}$. The $\mathrm{CH}_{2}$ bending appear at $1398 \mathrm{~cm}^{-1}$. The asymmetric stretching mode of sulphur appear at $1293 \mathrm{~cm}^{-1}$. The peak appear at $1123 \mathrm{~cm}^{-1}$ is associated with C-N stretching. The peaks at $901,811 \mathrm{~cm}^{-1}$ strongly suggest the presence of C-C stretching mode. The peaks at $764,680,618,508 \mathrm{~cm}^{-1}$ corresponds to $\mathrm{NH}_{3}{ }^{+}$for torsional oscillations. FTIR intensity and frequencies of the grown TGS crystal matches with the reported literature [39]. The FTIR assignments of the grown TGS crystal are given in Table.1

Table. 1 FTIR Assignments of the grown TGS crystal

\begin{tabular}{|c|c|l|}
\hline $\begin{array}{c}\text { Wave number }\left(\mathbf{c m}^{-\mathbf{1}}\right) \\
\text { observed }\end{array}$ & $\begin{array}{c}\text { Wave number }\left(\mathbf{c m}^{-\mathbf{1}}\right) \\
\text { Reported }[\mathbf{2 1}, \mathbf{3 4}, \mathbf{3 9}]\end{array}$ & \multicolumn{1}{c|}{ Assignments } \\
\hline 3423 & 3405 & $\left(\mathrm{NH}_{3}\right)^{+}$anti symmetric stretching \\
\hline 3169 & 3173 & $\left(\mathrm{NH}_{3}\right)^{+}$symmetric stretching \\
\hline 3009 & 2914 & $\mathrm{CH}_{2}$ stretching \\
\hline 2911 & 2636 & $\mathrm{NH}_{3}+$ overtones and combination bands \\
\hline 2611 & 2783 & \\
\hline 2705 & 1568 & $\mathrm{C}-\mathrm{O}$ stretching of COOH group \\
\hline 1596 & 1518 & $\left(\mathrm{NH}_{3}\right)^{+}$anti sym. bending \\
\hline 1517 & 1329 & $\mathrm{CH} 2$ bending \\
\hline 1398 & 1309 & $\mathrm{~S}=\mathrm{O}$ asymmetric stretching \\
\hline 1291 & 1118 & $\mathrm{C}-\mathrm{N}$ stretching \\
\hline 1123 & 901 & $\mathrm{C}-\mathrm{C}$ stretching \\
\hline 901 & & \multicolumn{1}{|c|}{} \\
\hline 811 & &
\end{tabular}

National Conference on Current Advancements in Physics $3^{\text {rd }} \& 4^{\text {th }}$ February 2017 47 | Page

Department of Physics, St. John's College, Palayamkottai-627 002, Tamilnadu, India. DOI 10.9790/4861-17002034651 


\begin{tabular}{|l|l|l|}
\hline 680 & 669 & $\mathrm{NH}_{3}^{+}$torsional oscillation \\
\hline 618 & 615 & $\begin{array}{l}\mathrm{C}_{2} \text { out of Plane bending }+\mathrm{C}_{2} \mathrm{~N} \text { torsion }+\mathrm{C}_{10} \text { out of } \\
\text { plane bending }\end{array}$ \\
\hline 508 & 500 & $\mathrm{C}_{1} \mathrm{~N}$ torsion $+\mathrm{N}_{2} \mathrm{H}$ out of Plane bending \\
\hline
\end{tabular}
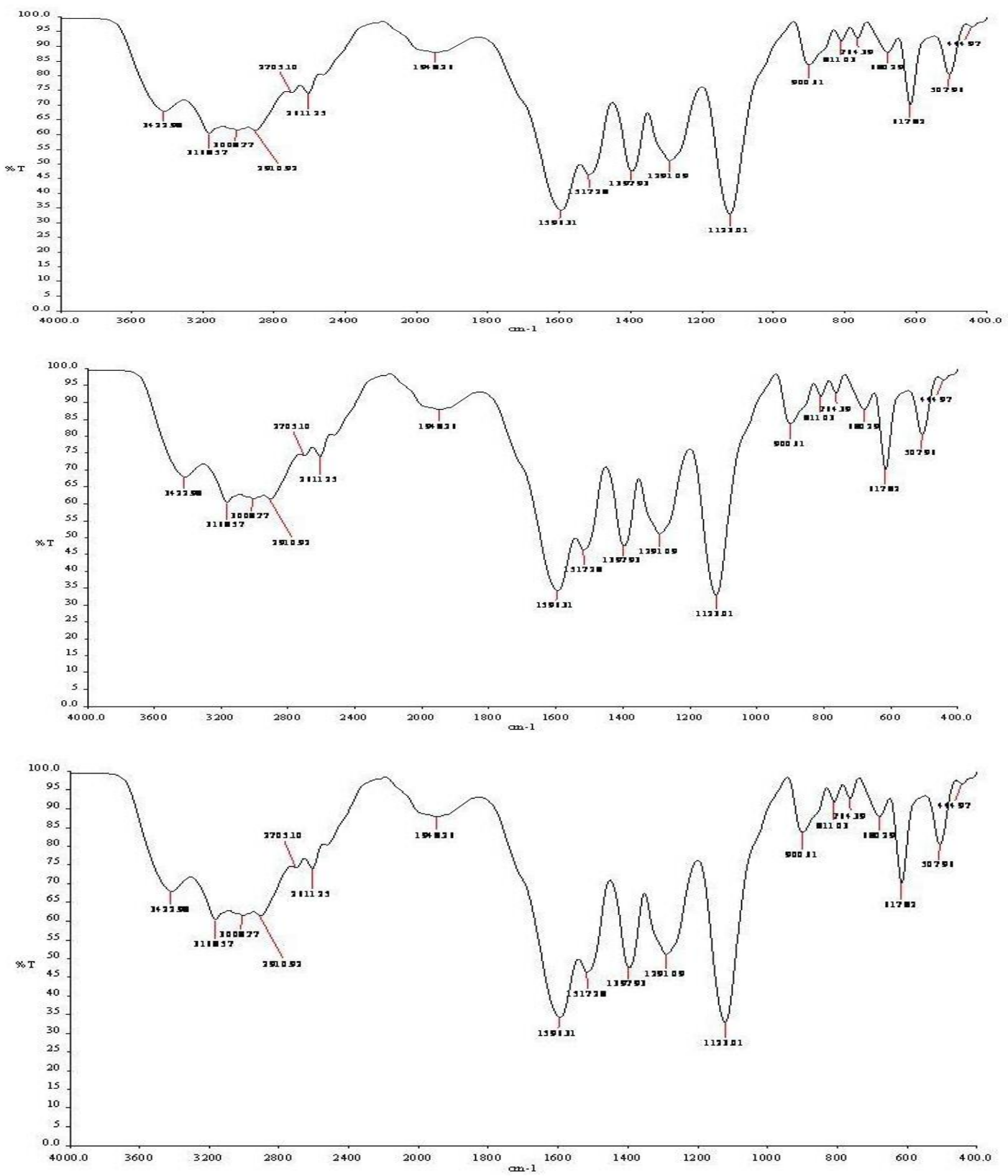

Fig. 3 FTIR spectrum of the grown TGS crystal

\section{Micro hardness Analysis}

Hardness of a material is a measure of resistance, that offers to deformation. The Vicker's hardness value $\left(\mathrm{H}_{\mathrm{V}}\right)$ was found out from the relation,

$$
\mathrm{H}_{\mathrm{v}}=1.8544 \frac{p}{d^{2}} \mathrm{Kg} / \mathrm{mm}^{2}
$$

Where $\mathrm{P}$ is the applied load and $\mathrm{d}$ is the average diagonal length [40]. The variation of microhardness with the applied load is shown in Fig.3.4.

It is evident from the plot that the Vickers hardness number increases with increasing applied load, thus it exhibit reverse indentation size effect (RISE). At low loads nucleation of dislocations formed along the particular slip system, but with increasing load, dislocation multiplication extends to other inner layers also. 
Above $100 \mathrm{gm}$, cracks were developed on the smooth surface of the crystal due to the release of internal stresses generated locally of indentation. According to Meyer's law [41],

$$
\begin{aligned}
& \mathrm{P}=\mathrm{K}_{1} \mathrm{~d}^{\mathrm{n}} \\
& \log \mathrm{P}=\log \mathrm{K}_{1}+\mathrm{nlog} \mathrm{d} .
\end{aligned}
$$

Where $\mathrm{P}$ is the applied load, $\mathrm{d}$ is the diagonal length of indentation, $\mathrm{K}_{1}$ is the standard hardness and $\mathrm{n}$ is the work hardening co-efficient has been found out using the slope of $\log \mathrm{d}$ vs $\log \mathrm{P}$ plot (Fig.3.5).
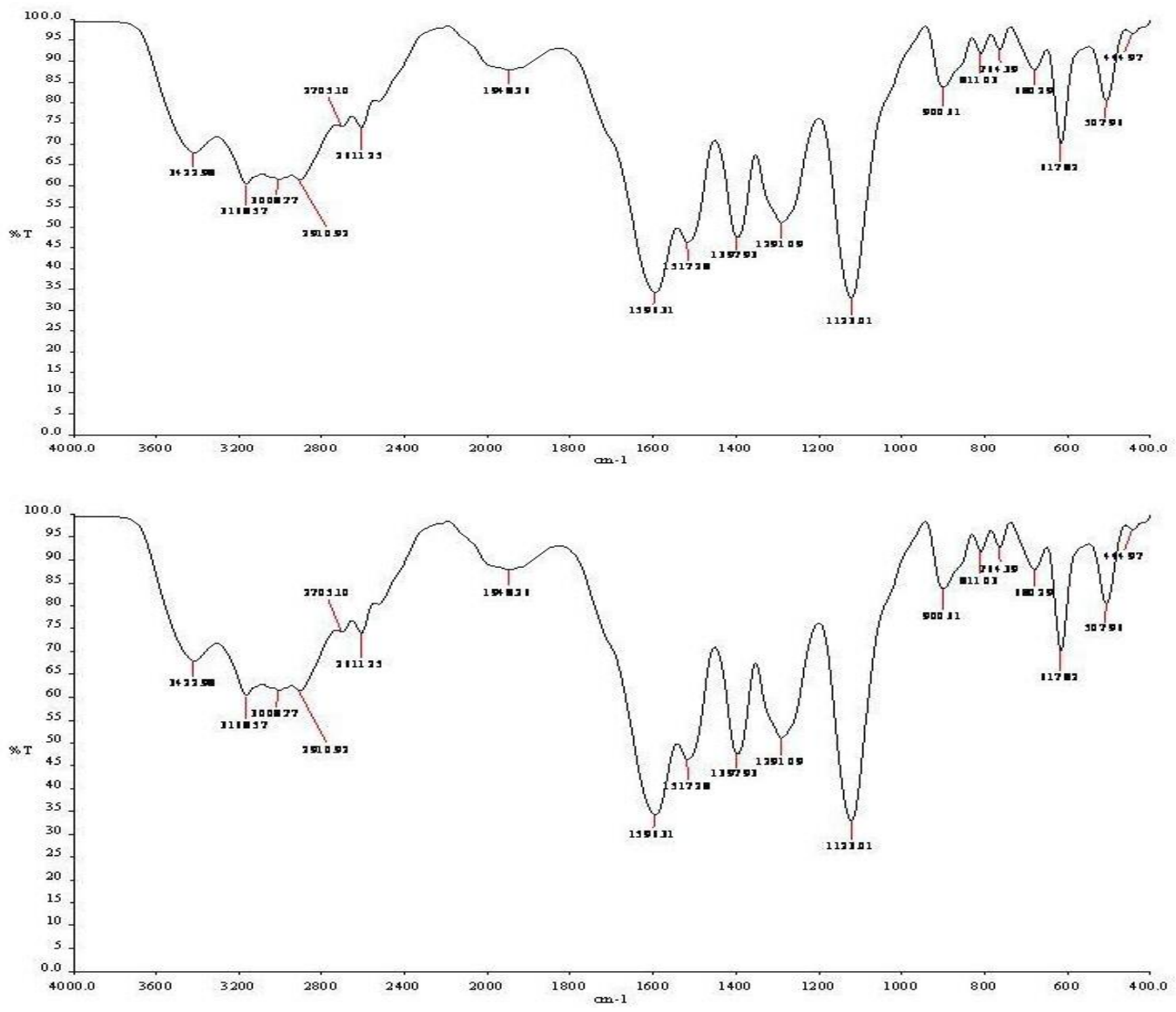

Fig.4 Variation of microhardness value with the applied load

From careful observation on different materials, Onitsch [42] pointed out that $\mathrm{n}$ lies between 1 and 1.6 for moderately hard materials, and it is more than 1.6 for soft materias. In the present study, the value of $n$ is 2.76, suggest that the grown TGS crystal belongs to soft material category. The yield strength $\left(\square_{v}\right)$ is determined using the relation [43],

$$
\square_{\mathrm{v}}=\mathrm{H}_{\mathrm{v}} / 2.9\left\{[1-(\mathrm{n}-2)] \times\left[12.5(\mathrm{n}-2) /_{1-(\mathrm{n}-2)}\right]^{\mathrm{n}-2}\right\}
$$

The yield strength of the grown TGS crystal has been estimated as87.80 MPa.

\section{Conclusion}

The Triglycine sulfate (TGS) crystal has been grown by the conventional slow evaporation technique. Its identity was confirmed by powder XRD technique. It is crystallized in monoclinic system with space group

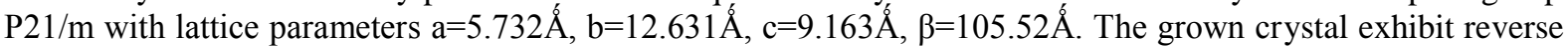
indentation size effect. Micro hardening coefficient determines that it belongs to soft material category. 

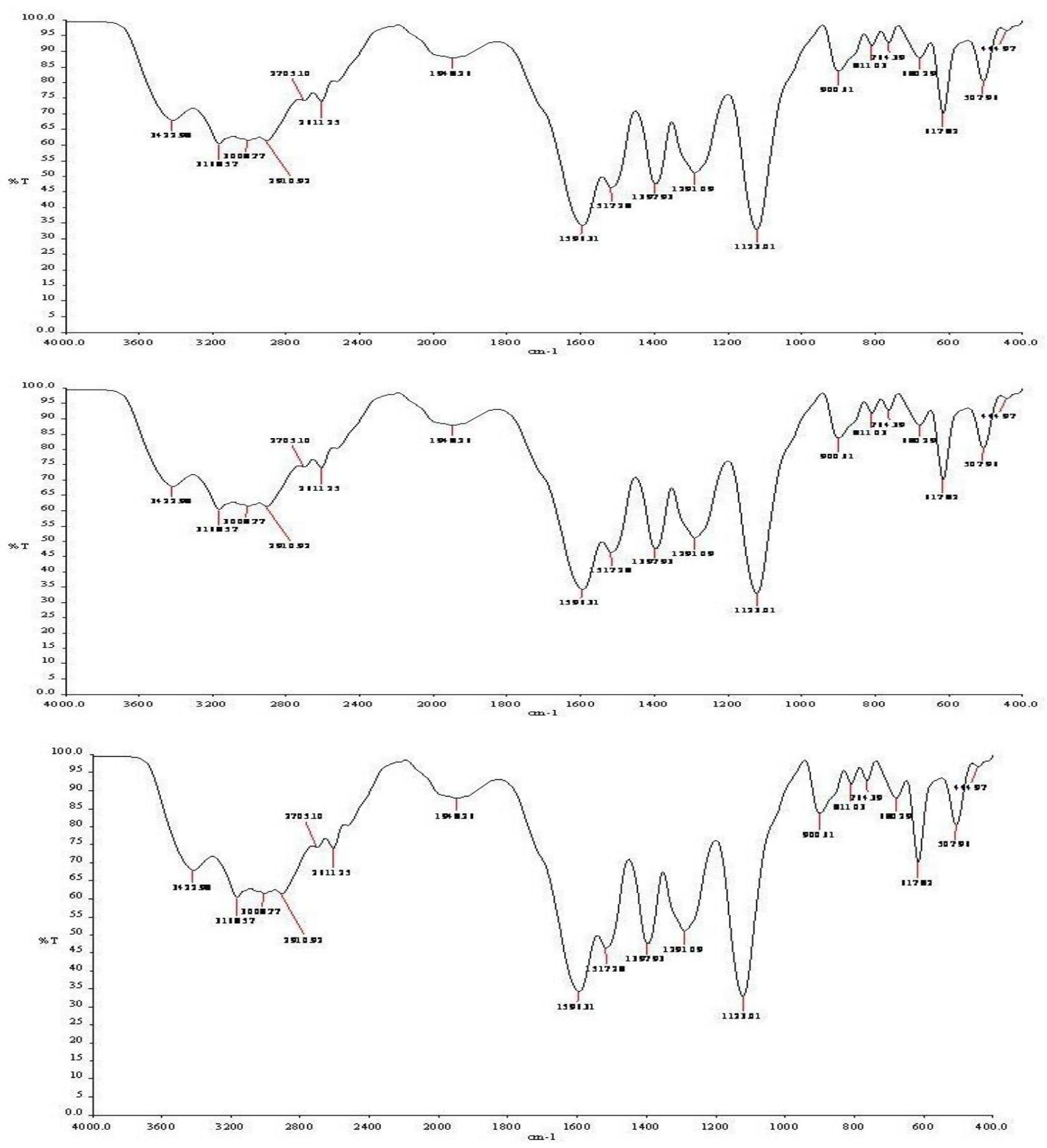

Fig.5 $\log$ P Vs log d plot for the grown TGS crystal

\section{Bibliography}

[1]. N. P. Rajesh, C. K. Mahadevan, P. Sanathana Raghavan, Yen-Chieli Huang, P. Ramasamy, Mat. Lett. 55 (2002) $394-$ 396.

[2]. K.B. Ashok, D.A.Mohan and B.L. Ravindra, Mat. Lett. 57 (2003) 3943-3948.

[3]. C.Berbacaru, H.V. Alexandru, L.Pintilie, A.Duttu, B.Logofatu and R.C. Radulescu, Mat. Sci. and Eng. 118 (2005) $141-146$.

[4]. M. A. Gaffar, A. A. Al-Fadl, Cryst. Res. Tech. 34 (1999) 915-923.

[5]. E. A. Wood, A. N. Holder, Acta Cryst. Vol.10 (1957) 145-146.

[6]. G. Hofmann, N. Neumann and H. Budzier, Ferro electrics 133 (1992) 41-45

[7]. H. V.Alexander and C. Berbecaru, Mat. Sci. Semicond. Process 5 (2002) 159-165.

[8]. N. Balamurugan, M. Lenin, G. Bhagavannarayana and P. Ramasamy, Crys. Res. Tech. 42 (2007) 151-156.

[9]. P. Selvarajan, B. N. Das, H. B. Gon and K. V. Rao, J. Mat. Sci. Lett. 11 (1992) 1312-1314.

[10]. N. Nakatani, Jpn. J. Appl. Phys. 29 (1990) 2774.

[11]. R. Le Bihan, Ferro electrics 97 (1989) 19.

[12]. S. Hoshino, Y. Okaya, R. Pepinsky, Phys. Rev. 115 (1959) 323.

[13]. C.S. Fang, H. Liu, H. S. Zhuo, M, Wang D. Xu, Crys. Res. Tech. 30 (1993) 785-789.

[14]. C. M. Ragavan, R. Sankar, R. Mohan Kumar and R. Jeyavel, Mat. Res. Bull. 43 (2008) 305-311.

[15]. S. Aravazhi, R. Jeyavel, C. Subramanian, Ferro electrics 200 (1997) 279-286. 
[16]. R. B. Lal, A. K. Batra, Ferro electrics 142 (1993) 51-82.

[17]. M. A. Gaffar, A. A. El-Fadl, S. A. Monsour, Journal of Physics D: App.Phys. 22 (1989) 327-336.

[18]. M. S. Pandian, N. Balamurugan, V. Ganesh, P.V. Rajasekhar, K. K. Rao, P. Ramasamy, Mat. Lett. 62 (2008) 38303832.

[19]. K. Biedzycki, Solid state Communication 118 (2001) 141-144.

[20]. N. Theresita Shanthi, P. Selvarajan, C. K. Mahadevan, Ind. J. Sci. and Tech. 2 (2009) 49-52.

[21]. V. Krishna Kumar, M. Rajaboopathy, R. Nagalakshmi, Adv. Mat. Lett. 2 (2011) 163-169.

[22]. P. Manoharan, N. Neelakanda Pillai, Sch. Res. Lib. Arch. App. Sci. Res. 5 (2013) 93-97.

[23]. Farhana Khanum, Jiban Podder, J. Crystallization Proc. and Tech. 1 (2011) 26-31.

[24]. M. Krishna Mohan, S. Ponnusamy, C. Muthamizhchelvan, Int. J. Chem. Tech. Res. 7 (2014) 1488-1494.

[25]. D. Arul Asir Abraham, U. Sankar, S. Perumal, P. Selvarajan, Int. J. Chem. Tech. Res. 7 (2014) 1702-1707.

[26]. P. R. Deepthi, J.Shanthi, Eur. Int. J. Sci. and Tech. 2 (2013) 201-207.

[27]. X. Sun, M. Wang, Q. W. Pan, W. Shi, C. S. Fang, Crys. Res. Tech. 34 (1999) 1251-1254.

[28]. R.Muralidharan, R. Mohan Kumar, P. M. Usha Sree, R. Jeyavel, P. Ramasamy, J. Cryst. Growth 234 (2002) 545550.

[29]. V. N. Shut, I. F. Kashevich, S. R. Syrtsov, Physics of the Solid State 50 (2008) 118-121.

[30]. A. Saxena, V. Gupta, K. Sreenivas, J. Cryst. Growth 263 (2004) 192-202.

[31]. K. Meera, S. Aravazhi, P. Santhana Raghavan, P. Ramasamy, J. Cryst. Growth 211 (2000) 220-224.

[32]. K. Meera, R. Muralidharan, P. Santhanaraghavan, R. Gopalakrishnan, P. Ramasamy, J. Cryst. Growth 226 (2001) 303-312.

[33]. J. Novotny, L. Prokopova, Z. Micka, J. Cryst. Growth 226 (2001) 333-340.

[34]. K. Meera, R. Muralidharan, A. K. Tripathi, P. Ramasamy, J. Cryst. Growth 263 (2004) 524-531.

[35]. S. Genbo, H. Youping, Y. Hongshi, S. Zikhong, E. J. Qingin, J. Cryst, Growth 209 (2000) 220-222.

[36]. Toshio Kikutu, Toshinari Yamazaki, Noriyuki Nakatani, J. Cryst. Growth 313 (2010) 20-25.

[37]. K. Meera, A. Claude, R. Muralidharan, C. K. Choi, P. Ramasamy, J. Cryst. Growth 285 (2005) 358-364

[38]. J. Stankowska, E. Peter and M. Trybula, Acta Physica Polonica A 97 (2000) 1061-1072.

[39]. J. Bharthasarathi, V. Siva Shankar, R. Jeyavel, P. Muruga Koothan, J. Cryst. Growth 311 (2009) 1147-1151.

[40]. D. Tabor, 'The Hardness of Materials', Oxford University Press, Oxford (1951).

[41]. E. Meyer, Z. Ver, Dtsh. Ing. 51 (1908) 645.

[42]. E. M. Onitsch, Mikroscopie 2 (1947) 131-151.

[43]. O. Sahin, O. Uzun, U. Koleman, N. Ucar, Mat. Characterization 59 (2008) 427-434. 